\title{
AUTISM Spectrum Disorders and Suicidality
}

\author{
Michele Raja ${ }^{1, *}$, Antonella Azzoni ${ }^{2}$ and Alessandra Frustaci ${ }^{3}$ \\ ${ }^{1}$ Scuola di Specializzazione in Psichiatria, Università degli Studi di Roma "La Sapienza", Via Prisciano 26, 00136 - \\ Rome, Italy; ${ }^{2}$ Servizio Psichiatrico di Diagnosi e Cura, Ospedale Santo Spirito in Sassia, Via Ugo De Carolis 70, \\ 00136, Rome, Italy; ${ }^{3}$ Section of Clinical and Molecular Epidemiology-IRCCS San Raffaele Pisana, Rome, Italy
}

\begin{abstract}
The paper describes the suicidal ideation and behavior in a series of 26 adult psychiatric patients affected by Autism Spectrum Disorders (ASDs), the clinical features and the psychiatric comorbidity of patients presenting suicidal behavior, and the history of suicide or suicide attempt in their relatives. Two $(7,7 \%)$ patients committed suicide. One (3.8\%) patient attempted suicide twice, and one (3.8\%) patient self-harmed by cutting his face and one finger of his hand with a razor. Eight $(30.8 \%)$ patients presented suicidal ideation. Two $(7.7 \%)$ patients had one relative who had attempted suicide, and two $(7.7 \%)$ patients had one or more relatives who had committed suicide. Most patients with suicidal behavior or ideation presented psychotic symptoms. Although it is not clear whether the high suicidal risk is related with ASDs per se or with psychotic symptoms, a high index of suspicion is warranted in evaluating suicidal risk in patients affected by ASDs, whatever is their age, psychiatric comorbidity, and setting of visit.
\end{abstract}

Key Words: Autism spectrum disorders, Pervasive developmental disorders, Psychotic signs, Schizophrenia, Suicide.

\section{INTRODUCTION}

There are few reports on suicidal behavior among patients with Autism Spectrum Disorders (ASDs). Causes of under-reporting may be the low rate of suicidal behavior among children and pre-adolescents and the underdiagnosing of ASDs in the adult psychiatric setting.

Suicide is rare in childhood and early adolescence, and becomes more frequent with increasing age. Worldwide annual rates of suicide are respectively 0.5 per 100,000 for females and 0.9 for males among 5-14-year-olds, and 12.0 for females and 14.2 for males among 15-24-year-olds [1].

A systematic review of the literature [2] on the prevalence of suicidal phenomena in adolescents (128 studies, comprising 513,188 adolescents), found that the mean proportion of adolescents reporting having attempted suicide at some point in their lives was 9.7\% (95\% CI, 8.5-10.9), whilst $29.9 \%$ (95\% CI, 26.1-33.8) of adolescents said they had thought about suicide at some point.

Only few studies examined suicidal behavior of children and adolescents affected by ASDs. In a study [3] on 126 children referred to a child psychiatric ward because of suicidal behavior, 123 (97\%) were diagnosed as having at least one definite psychiatric diagnosis. Children with suicidal behavior made out $6 \%$ of all referred male and females children. Among them, 7 boys suffered from psychoses and Pervasive Developmental Disorders (PDDs), whilst the rest of the boys suffered from attention deficit and hyperactivity disorders or mixed disorders of conduct and emotions.

Hardan \& Sahl [4] examined suicidality in a clinically referred sample of children and adolescents and found that 47

*Address correspondence to this author at Scuola di Specializzazione in Psichiatria, Università degli Studi di Roma "La Sapienza", Via Prisciano 26, 00136 - Rome, Italy; Tel/Fax: +39 065898721; Mob: + 39 3473422158. Email: michele.raja@ libero.it; michele.raja@ fastwebnet.it.
(20\%) patients experienced either suicidal ideation, threats, or attempts. They observed suicidality more often in individuals with oppositional defiant disorder, depressive disorder, and post traumatic stress disorder, and less often in the autistic and the severely mentally retarded groups. They observed suicidal behavior frequently in children and adolescents with developmental disabilities other than Autistic Disorder (AD), however.

In a consecutive study [5] of adolescents who had attempted suicide and had been hospitalized for inpatient treatment, 12 of the 94 subjects (12.8\%) were affected by PDDs.

To our knowledge, there is no study on suicidal behavior among adult people with ASDs, possibly because psychiatrists caring adult people are not familiar with the diagnosis. In fact, ASDs are usually considered a condition of childhood and the diagnosis and treatment of ASDs has only recently gained attention also in adult psychiatry.

The awareness of the ASDs diagnosis has been considered contingent on certain key professionals, who are interested in the area [6]. Patients with ASDs attending psychiatric services for adult people often receive a dual diagnosis, but most of them are diagnosed late or are wrongly considered to have schizophrenia [7]. Actually, these patients are clinically more similar to psychiatric patients affected by schizophrenia, mood, or obsessive compulsive spectrum disorders than to patients with ASDs attending neuropsychiatric services for children and adolescents or autism and developmental centers, who don't have a dual diagnosis.

The aims of the present study are: (a) to describe suicidal ideation and behavior in a relatively large series of adult psychiatric patients with ASDs; (b) to describe the clinical features of patients presenting suicidal behavior and evaluate their psychiatric comorbidity; (c) to assess history of suicide or Suicide Attempt (SA) in their relatives. 


\section{METHODS}

\section{Sample Selection}

Since 1994 we studied intensively all consecutive subjects who presented symptoms of ASDs in the Psychiatric Intensive Care Unit (PICU) of a general hospital and in private practice. According to DSM-IV diagnostic criteria and associated features of AD or Asperger's Syndrome (AS), we considered signs suggestive of PDDs the following: impairment in communication or social interactions, failure to develop adequate peer relationships, lack of spontaneous seeking to share enjoyment, interests, or achievements with other people, lack of social or emotional reciprocity, restricted repetitive or stereotyped patterns of behavior, interests, and activities, cognitive verbal and non verbal impaired abilities and super-abilities; clumsy, uncoordinated movements; repetitive behavior, atypical obsessions or compulsions, and stereotypies.

Furthermore, we included in our diagnostic criteria good sense of humor; ability to imitate, and history of several inconsistent psychiatric diagnoses on the basis of our personal experience with patients affected by ASDs, visited in the adult psychiatric setting. Whenever we recognized one of these clinical features, we made intensive clinical assessment, including medical charts review and interview with patient's relatives to confirm the diagnosis. The diagnoses according to DSM-IV-TR were made by agreement of two authors who are senior neurologists and psychiatrists (MR, AA). Subjects with PDDs present heterogeneous symptoms and the categorical boundaries among the most common PDDs - AS, AD, PDDs-Not Otherwise Specified (NOS) lack of diagnostic validity. These disorders lie on an autism spectrum [8-10]. Walker et al. [11] found even the residual class of PDDs-NOS highly heterogeneous. Accordingly, we neglected this uncertain subtyping and chose to use in the analysis the generic diagnosis of ASDs which is more and more utilized in the current research [12].

\section{Comparisons and Assessment}

\section{Patients with ASDs vs all Other Patients}

In order to compare patients with ASDs and patients with other diagnoses, we considered only the 11 patients admitted to the PICU, because patients visited in the private practice were not always assessed using rating scales. In the comparison, we considered socio-demographic (age, gender, civil status, parenthood), and clinical variables [Brief Psychiatric Rating Scale, Scale for the Assessment of Positive Symptoms, Scale for the Assessment of Negative Symptoms, Mini Mental State Examination, Clinical Global Impression (CGI), Global Assessment of Functioning (GAF), Morrison's scale [13], Unified Parkinson's Disease Rating Scale, Barnes Akathisia Scale, daily dose of antipsychotic treatment expressed in chlorpromazine-equivalents [14] on admission and on discharge]. Regarding relative oral potency of $2^{\text {nd }}$ generation antipsychotics, we considered chlorpromazine $100 \mathrm{mg}$ equivalent to clozapine $50 \mathrm{mg}$, risperidone $1.6 \mathrm{mg}$, sertindole $3.2 \mathrm{mg}$, olanzapine $5 \mathrm{mg}$, quetiapine $200 \mathrm{mg}$, amisulpride $200 \mathrm{mg}$, aripiprazole $7.5 \mathrm{mg}$. We registered patients' previous SAs. Furthermore, we asked patients whether in the previous month they had: a) wished to die, b) thought about suicide in general, c) thought about methods for possible suicide, d) attempted suicide or self-harmed anyway. Patients with $\geq 2$ positive answers were considered with explicit suicidal risk. Although we collected the data prospectively to study suicidal behavior in ASDs patients with dual diagnosis, we conducted the present study retrospectively through use of record charts. All patients gave oral consent to participate to the study and collaborate fully.

\section{Statistical Analysis}

All data were entered into a SPSS database. An alpha of 0.05 was used for all statistical analyses. Only non parametric tests were used, because the distribution of the variables was not normal. Demographic and clinical features were compared across groups using Chi-Square test and Fisher's exact test for categorical variables and Mann-Whitney $U$ test for continuous variables.

\section{RESULTS}

\section{Suicidality in Patients with ASDs.}

In the last 15 years, we diagnosed ASDs in 26 subjects [25 men, 1 woman; mean age $( \pm \mathrm{SD})$ : 30.2 years $( \pm 9.8)$; mean years of education $( \pm \mathrm{SD})$ : 11.7 years $( \pm 7.1)$; mean I.Q. $( \pm \mathrm{SD})$ : total: 83.5 ( \pm 18.2$)$; verbal: $92.0( \pm 19.4)$; non-verbal: $75.9( \pm 19.2)]$. Sixteen subjects received a DSM-IV-TR diagnosis of AS, 5 of AD, and 5 of PDDs-NOS.

Table 1 reports gender, age, ASDs diagnosis, suicidal ideation or behavior, psychiatric symptoms in relatives, delusions, hallucinations, and disorganized thought. Table 2 reports years of education, child/adolescent history, social, cognitive and psychological functioning, and I.Q. Two $(7,7 \%)$ patients committed suicide, one, affected by PDDsNOS, schizophrenia and alcohol abuse by jumping from a bridge, and one, affected by AS and schizophrenia, by disembolwement. Total I.Q. was 96 in the former (verbal I.Q. 108, non verbal I.Q. 80) and 75 in the latter (verbal I.Q. 89, non verbal I.Q. 66). One (3.8\%) patient, affected by mood disorder with psychotic signs, with total I.Q. 103 (verbal I.Q. 107, non verbal I.Q. 98), attempted suicide twice, cutting and injecting air in his veins. One $(3.8 \%)$ patient, affected by mood disorder with psychotic signs, with total I.Q. 80 (verbal I.Q. 85, non verbal I.Q. 76), cut his face and one finger of his hand with a razor. Eight $(30.8 \%)$ patients presented suicidal ideation. Two $(7.7 \%)$ patients had one relative who had attempted suicide, and two $(7.7 \%)$ patients had one or more relatives who had committed suicide.

In their lifetime, twenty-one of $26(80.8 \%)$ subjects presented delusions and nineteen of $26(73 \%)$ presented hallucinations. Among the $22(84.6 \%)$ cases who presented hallucinations or delusions, 16 received a concurrent diagnosis of schizophrenia and 6 of mood spectrum disorder with psychotic signs. Other concurrent diagnoses were obsessivecompulsive disorder (OCD) (n. 2), and substance abuse disorder (n. 4). Positive psychotic symptoms were reported among relatives of $5(19.2 \%)$ patients and a mood disorder diagnosis among relatives of $8(30.8 \%)$ patients. Schizophrenia had been diagnosed in a relative of one patient $(3.8 \%)$. We did not find any difference among patients with and without suicidality regarding the considered sociodemographic or clinical variables, except for anxiety which 
Table 1.

\begin{tabular}{|c|c|c|c|c|c|c|}
\hline $\begin{array}{c}\text { Age, } \\
\text { Gender, } \\
\text { Diagnosis }\end{array}$ & Suicidality & $\begin{array}{l}\text { Psychiatric } \\
\text { Comorbidity }\end{array}$ & Psychiatric Familiarity & Delusions & Hallucinations & $\begin{array}{c}\text { Conceptual } \\
\text { Disorganization }\end{array}$ \\
\hline $\begin{array}{c}33 \hat{\jmath} \\
\mathrm{AD}\end{array}$ & & $\begin{array}{l}\text { Schi, OCD, } \\
\text { alcohol abuse }\end{array}$ & & $\begin{array}{l}\text { Persecution, } \\
\text { horror, sex }\end{array}$ & & \\
\hline $\begin{array}{c}20 \hat{\jmath} \\
\text { AS }\end{array}$ & $\begin{array}{l}\text { Suicidal idea- } \\
\text { tion }\end{array}$ & Schi & & Persecution, reference & Auditory & Circumstantiality \\
\hline $\begin{array}{l}42 \AA \\
\text { AS }\end{array}$ & & Schi & Grandmother: depression & $\begin{array}{l}\text { Religiosity; thought reading } \\
\text { and withdrawal }\end{array}$ & $\begin{array}{l}\text { Auditory, } \\
\text { Visual }\end{array}$ & Echolalia \\
\hline $\begin{array}{c}18 \delta \\
\text { PDD-NOS }\end{array}$ & & Schi & Father: SAD; sister: cyclothymia & Persecution, religiosity & Auditory & $\begin{array}{l}\text { Derailment, il- } \\
\text { logicality, inco- } \\
\text { herence }\end{array}$ \\
\hline $\begin{array}{l}31{ }^{\lambda} \\
\text { AS }\end{array}$ & & Schi & Mother: personality disorder NOS & Persecution & $\begin{array}{l}\text { Auditory, } \\
\text { visual }\end{array}$ & illogicality \\
\hline $\begin{array}{l}31 ठ^{\lambda} \\
\text { AS }\end{array}$ & & $\begin{array}{l}\text { Schi; substance } \\
\text { abuse }\end{array}$ & $\begin{array}{c}\text { Uncle: AS persecutory delusions } \\
\text { Aunt: persecutory delusions }\end{array}$ & Persecution & Auditory & $\begin{array}{l}\text { Illogicality, inco- } \\
\text { herence, tangen- } \\
\text { tiality }\end{array}$ \\
\hline $\begin{array}{l}230 \\
\text { AS }\end{array}$ & $\begin{array}{l}\text { Suicide by } \\
\text { disembowel- } \\
\text { ment }\end{array}$ & Schi & $\begin{array}{l}\text { Uncle: mental retardation; } \\
\text { Grandmother: alcoholism }\end{array}$ & Reference & Auditory, olfactory & \\
\hline $\begin{array}{c}36 \hat{\jmath} \\
\text { AS }\end{array}$ & $\begin{array}{l}\text { Suicidal idea- } \\
\text { tion }\end{array}$ & Schi & $\begin{array}{l}\text { Sister: anxiety } \\
\text { Father: PD-NOS }\end{array}$ & Reference & $\begin{array}{l}\text { Auditory, olfactory, } \\
\text { somatic, visual }\end{array}$ & $\begin{array}{l}\text { Illogicality, inco- } \\
\text { herence, tangen- } \\
\text { tiality }\end{array}$ \\
\hline $\begin{array}{l}34 \hat{\jmath} \\
\mathrm{AD}\end{array}$ & & Schi & & Persecution & Auditory & \\
\hline $\begin{array}{l}42 \hat{\jmath} \\
\text { AS }\end{array}$ & & Schi & $\begin{array}{c}\text { Mother: cold and strange, OCD } \\
\text { Father: depression } \\
2 \text { sisters: eating disorder }\end{array}$ & $\begin{array}{c}\text { Persecution, reference, guilt, } \\
\text { religiosity }\end{array}$ & Olfactory, somatic & $\begin{array}{c}\text { Circumstantiality, } \\
\text { tangentiality }\end{array}$ \\
\hline $\begin{array}{c}28 \hat{\sigma} \\
\text { PDD-NOS }\end{array}$ & Suicide by fall & $\begin{array}{c}\text { Schi, alcohol } \\
\text { abuse }\end{array}$ & Unknown & $\begin{array}{l}\text { Persecution, reference, religi- } \\
\text { osity, megalomania }\end{array}$ & & $\begin{array}{l}\text { Illogicality, inco- } \\
\text { herence, tangen- } \\
\text { tiality }\end{array}$ \\
\hline $\begin{array}{l}19 \text { ㅇ } \\
\text { AS }\end{array}$ & $\begin{array}{c}\text { Suicidal idea- } \\
\text { tion }\end{array}$ & $\begin{array}{c}\text { Mania with psy- } \\
\text { chotic signs }\end{array}$ & $\begin{array}{l}\text { Father and grandfather: anxiety, } \\
\text { depression, hypochondriasis } \\
\text { Uncle: paranoid delusions, SA }\end{array}$ & Sex, somatization & & \\
\hline $\begin{array}{c}25 \hat{\jmath} \\
\text { AS }\end{array}$ & & Depression & & Persecution and reference & Auditory & \\
\hline $\begin{array}{l}30 \AA \\
\mathrm{AD}\end{array}$ & $\begin{array}{c}\text { Suicidal idea- } \\
\text { tion }\end{array}$ & Depression & $\begin{array}{l}\text { Sister of grandmother: complete } \\
\text { isolation }\end{array}$ & Magic, esoteric content & $\begin{array}{c}\text { Auditory, olfactory, } \\
\text { visual }\end{array}$ & \\
\hline $\begin{array}{c}31 \sigma^{\pi} \\
\text { AS }\end{array}$ & $\begin{array}{l}\text { Suicidal idea- } \\
\text { tion }\end{array}$ & $\begin{array}{l}\text { Depression, agita- } \\
\text { tion, hostility }\end{array}$ & $\begin{array}{l}\text { Brother: PD-NOS; } \\
\text { Two cousins, son of a mother's } \\
\text { cousin: suicides }\end{array}$ & & & \\
\hline $\begin{array}{l}19 ð \\
\text { AS }\end{array}$ & $\begin{array}{l}\text { Suicidal idea- } \\
\text { tion }\end{array}$ & & Grandfather: SA & & & \\
\hline $\begin{array}{c}35 \text { ठ } \\
\text { AS }\end{array}$ & & Schi & $\begin{array}{c}\text { Father: depression } \\
\text { Mother:StPD, autistic behavior }\end{array}$ & & Olfactory & \\
\hline
\end{tabular}


Table 1.

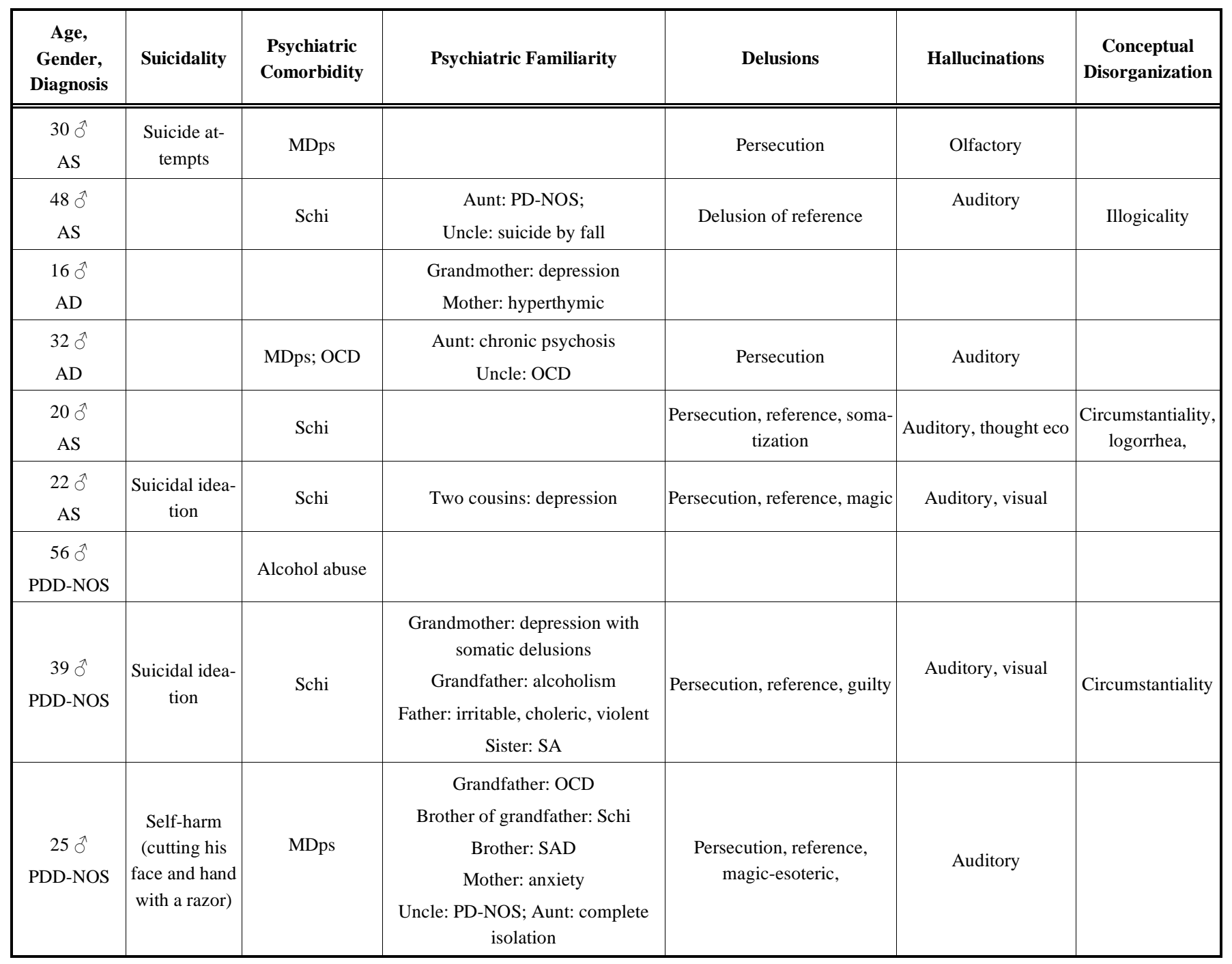

$\mathrm{AD}=$ Autistic disorder; AS = Asperger's syndrome; $\mathrm{BPD}=$ Borderline personality disorder; MDps $=$ Mood disorder with psychotic signs; $\mathrm{PD}-\mathrm{NOS}=\mathrm{Psychiatric}$ disorder not otherwise specified; PDD-NOS = Pervasive developmental disorder not otherwise specified; SAD = Schizoaffective disorder; Schi $=$ Schizophrenia; SdPD = Schizoid personality disorder; $\mathrm{OCD}=$ Obsessive-compulsive disorder; $\mathrm{StPD}=$ Schizotypal personality disorder;

is more frequent in patients with suicidality than in those without $(66.7 \%$ vs. $21.4 \%, \mathrm{p}=0.03)$.

\section{ASDs Patients Compared to all Psychiatric Patients}

Compared with patients admitted to the PICU who received other diagnoses, patients with ASDs were younger, mostly males, more frequently without children; They were more severely affected at the CGI score, and they had lower current GAF score and best GAF score in the last year (i.e., worse functioning), more severe negative symptoms, more retire/retard, and higher vulnerability to motor side effects of treatment with antipsychotics. Interestingly, they had never attempted suicide in the past but had more frequently suicidal ideation (5 out of $10 v s 622$ of 1502), even in a not statistically significant way.

\section{DISCUSSION}

To our knowledge, this is the first study on suicidal behavior in adult patients affected by ASDs. Several limita- tions of the study must be acknowledged. 1) Since patients with ASDs and no severe psychiatric comorbidity seldom seek assistance to adult psychiatry services, the sample of the study can be considered relatively large, but the absolute number of patients is actually small. 2) We did not use standardized diagnostic instruments because we choose to widen the spectrum of symptoms suggestive of ASDs and not to set rigid inclusion/exclusion criteria in order to increase the sensitivity of diagnostic assessment. Similar reasons prompted other authors to modify DSM- IV or ICD-10 criteria, to treat AS and High Functioning Autism interchangeably, or to use investigator-defined criteria, although, doing so, they make it difficult to compare studies [15]. Whenever we noted a symptom suggestive of ASDs, intensive clinical assessment allowed a reliable diagnosis of ASDs, according to DSM-IVTR. The discrepancy between verbal and non verbal I.Q. assisted the diagnosis of ASDs. 3) Since the reported patients are characterized by a high functioning level and most of them do not have mental retardation by IQ, the results of the study cannot be generalized to most patients affected by 
Table 2.

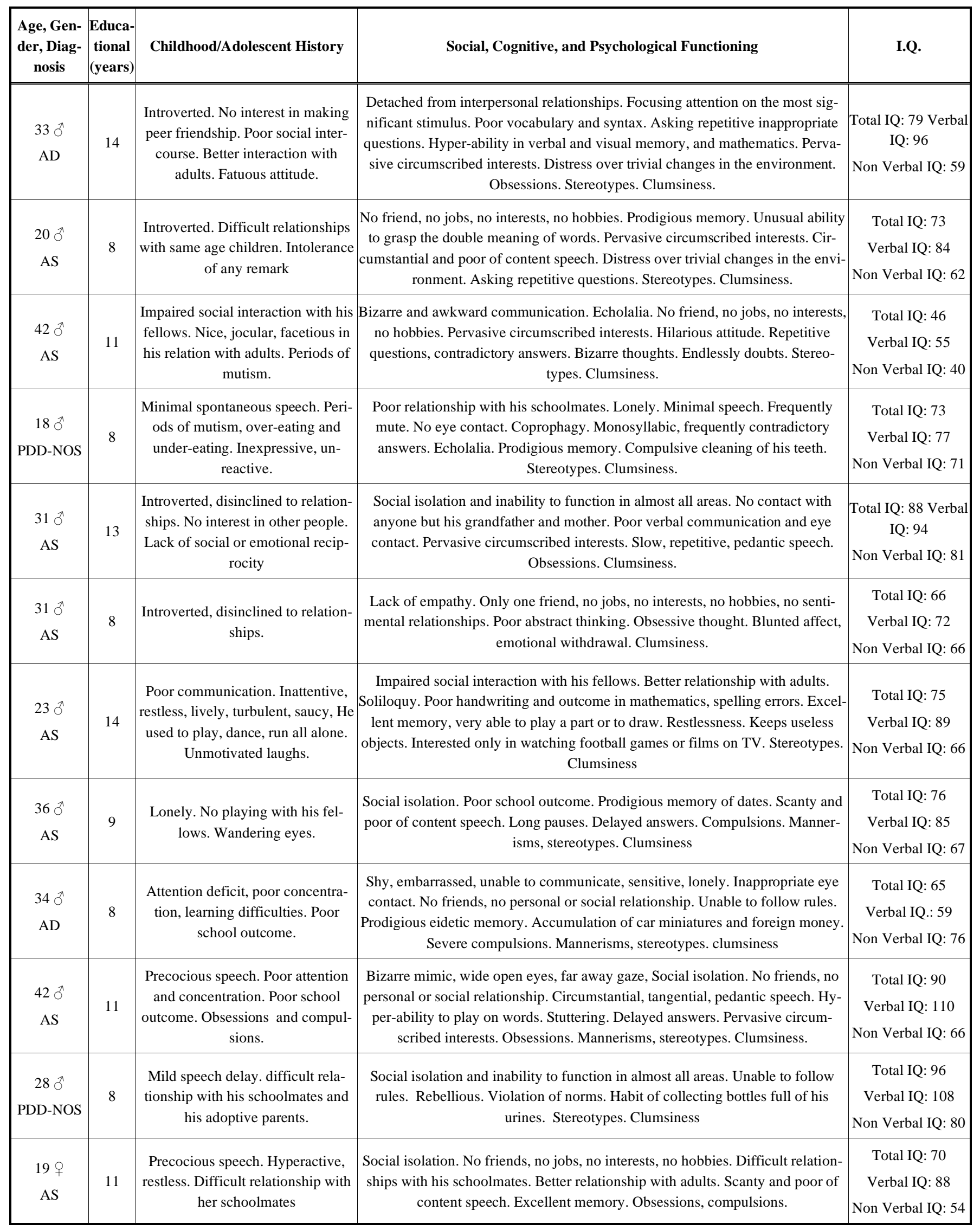


Table 2. contd...

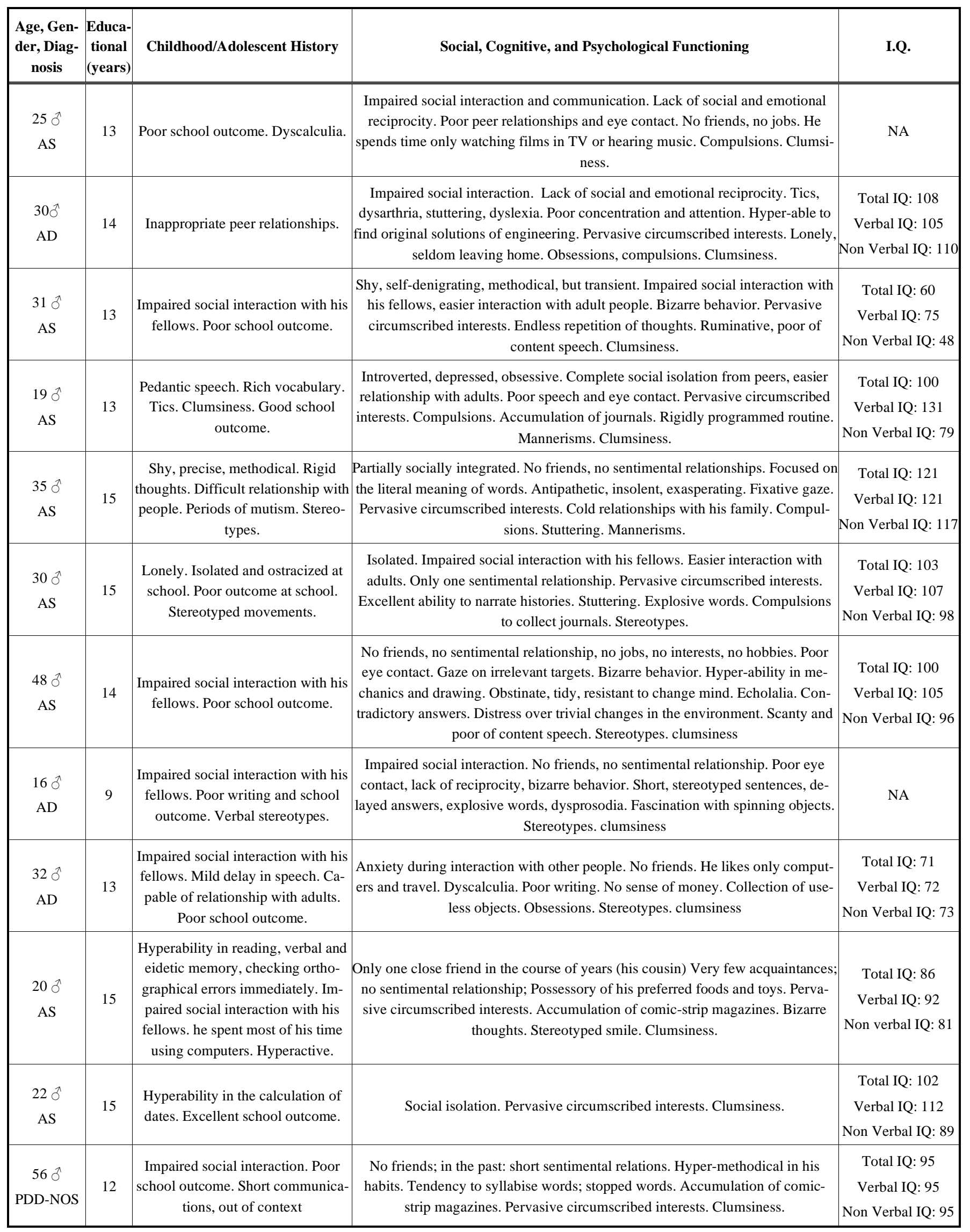


Table 2. contd...

\begin{tabular}{|c|c|c|c|c|}
\hline $\begin{array}{l}\text { Age, Gen- } \\
\text { der, Diag- } \\
\quad \text { nosis }\end{array}$ & $\begin{array}{c}\text { Educa- } \\
\text { tional } \\
\text { (years })\end{array}$ & Childhood/Adolescent History & Social, Cognitive, and Psychological Functioning & I.Q. \\
\hline $\begin{array}{c}39 \widehat{\sigma} \\
\text { PDD-NOS }\end{array}$ & 17 & $\begin{array}{l}\text { Impaired social interaction. Periods } \\
\text { of mutism. Hyper-ability in reading }\end{array}$ & $\begin{array}{l}\text { Stereotyped facial expression. Punctilious, pedantic, distractible, repetitive, } \\
\text { meticulous, uncreative. Pedantic speech. Stuttering. Pervasive circumscribed } \\
\text { interests. Accumulation of magazines. Obsessions. Clumsiness }\end{array}$ & NA \\
\hline $\begin{array}{l}250 \\
\text { PDD }\end{array}$ & 8 & $\begin{array}{l}\text { Impaired social interaction with his } \\
\text { fellows. Poor school outcome. }\end{array}$ & $\begin{array}{l}\text { Introverted, lonely, punctilious, pedantic, sensitive. Inappropriate, bizarre com- } \\
\text { munications. Memory talent. Previous unskilled jobs for short periods of time, } \\
\text { currently no job. Obsessions, compulsions. Clumsiness }\end{array}$ & $\begin{array}{c}\text { Total IQ: } 80 \\
\text { Verbal IQ: } 85 \\
\text { Non Verbal IQ: } 76\end{array}$ \\
\hline
\end{tabular}

$\mathrm{AD}=$ Autistic disorder; AS = Asperger's disorder; BPD = Borderline personality disorder; MDps = Mood disorder with psychotic signs; PD-NOS = Psychiatric disorder not otherwise specified; PDD-NOS = Pervasive developmental disorder not otherwise specified; SAD = Schizoaffective disorder; Schi $=$ Schizophrenia; SdPD $=$ Schizoid personality disorder; $\mathrm{OCD}=$ Obsessive-compulsive disorder; $\mathrm{StPD}=$ Schizotypal personality disorder; NA= Not available.

Table 3.

\begin{tabular}{|c|c|c|c|c|}
\hline & Patients with ASDs: 11 & Patients with Other Diagnoses: 2495 & $\chi^{2}$ or $\mathrm{U}$ & P-value \\
\hline Males & $10(90.9 \%)$ & $1133(45.4 \%)$ & 9.14 & $.004 \S .003 *$ \\
\hline Single & $11(100 \%)$ & $1752(77.9 \%)$ & 3.12 & $.136 \S .08^{*}$ \\
\hline Children & 0 & $743(38.6 \%)$ & 6.9 & $.009 \S .009 *$ \\
\hline Commitment & $3(27.3 \%)$ & $644(26 \%)$ & 0.01 & $1.00 \S .92 *$ \\
\hline Previous suicide attempt & No: 10 ; Yes: 0 & No: 1082 ; yes: 381 & 3.51 & $.05 \S .06^{*}$ \\
\hline Current suicidal ideation or behavior & No: 5 ; Yes: 5 & No: 880 ; yes: 622 & 0.30 & $.75 \S .58 *$ \\
\hline Age (years) & $28.9 \pm 9.1$ & $42.7 \pm 14.9$ & 6026 & .001 \\
\hline Years of education & $10.5 \pm 2.01$ & $11.05 \pm 4.02$ & 7240 & .7 \\
\hline CGI severity & $(n=10) 6.20 \pm 0.42$ & $(\mathrm{n}=2008) 5.73 \pm 0.62$ & 6431 & .009 \\
\hline CGI improvement & $(n=10) 2.20 \pm 1.03$ & $(n=1990) 2.20 \pm 1.04$ & 8811.5 & .5 \\
\hline Current GAF score & $(n=10) 18.7 \pm 6.3$ & $(\mathrm{n} .=1733) 23.5 \pm 8.1$ & 5422.5 & .04 \\
\hline Best GAF score in the last year & $(\mathrm{n}=10) 38.2 \pm 12.3$ & $(\mathrm{n} .=1474) 52.2 \pm 14.7$ & 3575 & .005 \\
\hline BPRS total score: & $(n=9) 64.2 \pm 10.5$ & $(\mathrm{n}=1423) 59.3 \pm 13.2$ & 4886.5 & .220 \\
\hline BPRS th score & $(n=9) \quad 10.7 \pm 4.1$ & $(n=1424) 10.7 \pm 5.2$ & 6173.5 & .849 \\
\hline BPRS rr score & $(n=9) 11.6 \pm 4.6$ & $(\mathrm{n}=1424) 6.6 \pm 4.1$ & 2490.5 & .001 \\
\hline BPRS hos score & $(\mathrm{n}=9) 7.3 \pm 4.0$ & $(n=1423) 8.0 \pm 3.7$ & 5780.5 & .613 \\
\hline BPRS ad score & $(n=9) 9.1 \pm 5.5$ & $(\mathrm{n}=1424) 9.5 \pm 4.5$ & 6119.5 & .815 \\
\hline SAPS score & $(n=9) 41.3 \pm 18.8$ & $(n=1423) 34.4 \pm 23.6$ & 4897.5 & .223 \\
\hline SANS score & $(n=9) 72.6 \pm 15.1$ & $(n=1424) 40.9 \pm 24.6$ & 1863.5 & $<0.001$ \\
\hline MMSE score & $(n=9) 27.7 \pm 2.1$ & $(n=1356) 26.7 \pm 3.2$ & 5083 & .383 \\
\hline UPDRS total score & $(n=9) 12.1 \pm 5.5$ & $(\mathrm{n}=1332) 5.5 \pm 5.8$ & 2122 & .001 \\
\hline UPDRS rigidity score & $(\mathrm{n}=9) 0.3 \pm 0.5$ & $(\mathrm{n}=1338) 0.4 \pm 0.6$ & 5763 & .792 \\
\hline UPDRS tremor score & $(n=9) 2.6 \pm 1.1$ & $(\mathrm{n}=1340) 1.2 \pm 1.4$ & 2412.5 & .001 \\
\hline UPDRS akinesia score & $(\mathrm{n}=9) 1.3 \pm 1.2$ & $(\mathrm{n}=1335) 0.7 \pm 1.0$ & 4069 & .05 \\
\hline BAS score & $(n=9) 0.9 \pm 1.2$ & $(\mathrm{n}=1335) 0.4 \pm 0.9$ & 4550 & .08 \\
\hline
\end{tabular}


Table 3. contd....

\begin{tabular}{|c|c|c|c|c|}
\hline & Patients with ASD: 11 & $\begin{array}{l}\text { Patients with Other Diagnoses: } \\
2495\end{array}$ & $\chi^{2}$ or $\mathrm{U}$ & P-value \\
\hline CPZ-eq dose on admission(mg) & $(n=10) 261.8 \pm 133.0$ & $(\mathrm{n}=1762) 257.0 \pm 282.4$ & 7143.5 & .298 \\
\hline CPZ-eq dose on discharge(mg) & $(n=10) 326.0 \pm 152.1$ & $(n=1832) 359.1 \pm 313.0$ & 8585 & .731 \\
\hline
\end{tabular}

BPRS = Brief Psychiatric Rating Scale; BPRS th = BPRS thought disorder cluster; BPRS rr = BPRS retard-retirement cluster; BPRS hos = BPRS hostility cluster; BPRS ad = BPRS anxiety-depression cluster; CGI: Clinical Global Impression; CPZ-eq = Chlorpromazine equivalent; GAF: Global Assessment of Functioning; MMSE = Mini Mental State Examination; n. = number; NA = Not assessed; SANS = Scale of Assessment of Negative Symptoms; SAPS = Scale of Assessment of Positive Symptoms; UPDRS = Unified Parkinson's Disease Rating Scale; BAS = Barnes Akathisia Scale; statistically significant p-values are in bold; $\chi 2$ =Chi -Square test; U= Mann-Whitney U test ; $\S$ Fisher's exact test; * Chi-square; data are shown in frequence (percentage) or mean \pm standard deviation.

autism or severe PDD. 4) The meaning of ASDs and schizophrenia comorbidity in adult people is debatable. The high rate of comorbidity between ASDs and schizophrenia in this sample might suggest that suicidal risk is related more with the comorbid diagnosis of schizophrenia than with ASDs per se. However, the high rate of comorbidity between ASDs and schizophrenia could be only an artifact due to the DSMIV-TR invalid exclusion of psychotic symptoms from the symptomatic spectrum of ASDs. Actually, if delusions or hallucinations had been considered features of ASDs, we would have always omitted the diagnosis of schizophrenia, since the ASDs diagnosis accounted for all the other symptoms. The relationship between ASDs and schizophrenia is still uncertain. While DSM-IV-TR considers ASDs distinct from schizophrenia, recent studies on comorbidity and familiarity join ASDs and schizophrenia again [16,17].

Despite these drawbacks, the study shows that suicidal behavior is highly prevalent in patients with ASDs attending psychiatric services for adult people. It is impressive the high suicide/SA ratio in this sample. In general, unsuccessful SAs outnumber completed suicides by a multiple by 16 [18]. According to Irwin \& Shafer [19], for every completed suicide, there may be 50 to $120 \mathrm{SAs}$, with a female preponderance. Although the sample is too small to draw any firm conclusion, several hypotheses could be made to account for this discrepancy: a) higher male prevalence, since the suicide/SA ratio is higher in males; b) younger age and comorbid diagnosis of schizophrenia, since the early phase of this illness is characterized by the highest risk of suicide; c) pervasive obsessive traits suggesting low level of impulsivity and possible higher degree of planning. From a behavioral standpoint, suicide attempters who plan suicide resemble those who complete suicide more than those who attempt suicide impulsively, both biologically and behaviorally [20].

We wish also to emphasize our surprise in being informed of the completed suicide of two patients, both of whom we had visited and treated in the previous months and for whom we had not realized their suicidal risk.

Possibly, suicidal behavior in patients with ASDs is related with specific clinical variables different from those typically observed in psychiatric patients affected by mood or schizophrenia spectrum disorders. This could mislead clinicians in their evaluation. It has been hypothesized that low self-esteem due to repeated serious social failures, feelings of isolation, and the "conflict" between patients and their parents are psycho-social predisposing factors [21].
Recognizing suicidal risk in ASDs patients may be difficult also because typical symptoms indicating impending suicidal risk can be masked by other symptoms. Impaired communication and social interactions, inappropriate or bizarre behavior, cognitive deficits, prominent negative symptoms can make ASDs patients not easily accessible to psychiatric evaluation. Prominent negative signs can hide under hopelessness, sadness, anguish, and suicidal intention. Neuroleptic-induced akinesia and poverty of speech can cover emotional turmoil and give a misleading impression of stability, quiescence, or even calmness.

The absence of a previous SA should not minimize concern about suicidal risk. Many individuals commit suicide on their first or second attempt [22]. In one population-based study of completed suicides, $56 \%$ of the individuals were successful on the first attempt [23].

The results of this exploratory study suggest that among adult patients affected by ASDs and attending psychiatric services suicide is frequent, the suicide/SA ratio is high, and the suicidal risk may be difficult to ascertain. Although it is not clear whether the high suicidal risk is related with ASDs per se or with psychotic symptoms, a high index of suspicion is warranted in evaluating suicidal risk in patients affected by ASDs, whatever their age, psychiatric comorbidity, and setting of visit. A great deal of work remains before the relationship between ASDs and schizophrenia can be understood. Future researchers will need to confirm our findings with larger samples and in different settings.

\section{LIST OF ABBREVIATIONS}

$\begin{array}{lll}\text { AD } & = & \text { Autistic Disorder } \\ \text { AS } & = & \text { Asperger's Syndrome } \\ \text { ASDs } & = & \text { Autism Spectrum Disorders } \\ \text { CGI } & = & \text { Clinical Global Impression } \\ \text { GAF } & = & \text { Global Assessment of Functioning } \\ \text { OCD } & = & \text { Obsessive-Compulsive Disorder } \\ \text { PDDs } & = & \text { Pervasive Developmental Disorders } \\ \text { PDDs-NOS } & = & \text { Pervasive Developmental Disorders } \\ \text { PICU } & = & \text { Psychiatric Intensive Care Unit } \\ \text { SA } & = & \text { Suicide Attempt }\end{array}$




\section{REFERENCES}

[1] Pelkonen M, Marttunen M. Child and adolescent suicide: epidemiology, risk factors, and approaches to prevention. Paediatr Drugs 2003; 5: 243-65.

[2] Evans E, Hawton K, Rodham K, Deeks J. The prevalence of suicidal phenomena in adolescents: a systematic review of populationbased studies. Suicide Life Threat Behav 2005; 35: 239-50.

[3] Høg V, Isager T, Skovgaard AM. Suicidal behavior in children--a descriptive study. Ugeskr Laeger 2002; 164: 5790-4.

[4] Hardan A, Sahl R. Suicidal behavior in children and adolescents with developmental disorders. Res Dev Disabil 1999; 20: 287-96.

[5] Mikami K, Inomata S, Hayakawa N, et al. Frequency and clinical features of pervasive developmental disorder in adolescent suicide attempts. Gen Hosp Psychiatry 2009; 31: 163-6.

[6] Engström I, Ekström L, Emilsson B. Psychosocial functioning in a group of Swedish adults with Asperger syndrome or highfunctioning autism. Autism 2003; 7: 99-110.

[7] Dossetor DR. 'All that glitters is not gold': misdiagnosis of psychosis in pervasive developmental disorders-a case series. Clin Child Psychol Psychiatry 2007; 12: 537-48.

[8] Miller JN, Ozonoff S. The external validity of Asperger disorder: lack of evidence from the domain of neuropsychology. J Abnorm Psychol 2000; 109: 227-38.

[9] Frith U. Emanuel Miller lecture: confusions and controversies about Asperger syndrome. J Child Psychol Psychiatry 2004; 45: 672-86.

[10] Macintosh KE, Dissanayake C. Annotation: the similarities and differences between autistic disorder and Asperger's disorder. A review of the empirical evidence. J Child Psychol Psychiatry 2004; 45: 421-34.

[11] Walker DR, Thompson A, Zwaigenbaum L, et al. Specifying PDDNOS: a comparison of PDD-NOS, Asperger syndrome, and autism. J Am Acad Child Adolesc Psychiatry 2004; 43: 172-80.

[12] Klin A. Subtyping the autism spectrum disorder. Theoretical, research, and clinical considerations. In: Goldstein S, Naglieri JA, \&
Ozonoff S, Eds., Assessment Of Autism Spectrum Disorders. New York, NY: The Guildford Press 2009; pp. 91-116.

[13] Morrison EF. A hierarchy of aggressive and violent behaviors among psychiatric inpatients. Hosp Community Psychiatry 1992; 43: 505-6.

[14] Baldessarini RJ. Chemotherapy in Psychiatry: Principles and Practice. Cambridge, Mass: Harvard University Press, 1985.

[15] Klin A, Pauls D, Schultz R, Volkmar F. Three diagnostic approaches to Asperger syndrome: implications for research. J Autism Dev Disord 2005; 35: 221-34.

[16] Kilpinen H, Ylisaukko-Oja T, Hennah W, et al. Association of DISC1 with autism and Asperger syndrome. Mol Psychiatry 2008; 13: 187-96.

[17] Rapoport J, Chavez A, Greenstein D, Addington A, Gogtay N. Autism spectrum disorders and childhood-onset schizophrenia: clinical and biological contributions to a relation revisited. J Am Acad Child Adolesc Psychiatry 2009; 48: 10-8.

[18] Meyers J, Stein S. The psychiatric interview in the emergency department. Emerg Med Clin North Am 2000; 18: 173-83.

[19] Irwin CE, Shafer MA. Adolesent health problems. In: Isselbacher KJ, Braunwald E, Wilson JD, Martin JB, Fauci AS, Kasper DL, Eds. Harrison's principles of internal medicine. New York: McGraw Hill 1994; pp. 27-28.

[20] Mann JJ. Violence and aggression. In: Bloom FE, Kupfer DJ, Eds. Psychopharmacology, The fourth generation of progress. New York: Raven Press 1995; pp. 1919-28.

[21] Mikami K, Ohya A, Akasaka K, Matsumoto H. Attempted suicide of youth with Asperger's disorder. Seishin Shinkeigaku Zasshi (Psychiatr Neurol Japonica) 2006; 108: 587-96.

[22] Janicak PG, Davis JM, Preskorn SH, Ayd FJ, Marder SR, Pavuluri MN. Principles and practice of psychopharmacology. 4th ed. Philadelphia: Lippincott Williams \& Wilkins; 2006.

[23] Isometsa ET, Lonnqvist JK. Suicide attempts preceding completed suicide. Br J Psychiatry 1998; 173: 531-5

Received: July 06, 2010

Revised: December 14, 2010

Accepted: January 04, 2011

(C) Raja et al.; Licensee Bentham Open.

This is an open access article licensed under the terms of the Creative Commons Attribution Non-Commercial License (http://creativecommons.org/licenses/by-nc/3.0/) which permits unrestricted, non-commercial use, distribution and reproduction in any medium, provided the work is properly cited. 